\title{
Flipping The Classroom: Turning An Instructional Methods Course Upside Down
}

Diane B. Marks, Appalachian State University, USA

\begin{abstract}
Higher education and teacher education in particular are entering a time of transformation. With major forces like shifting demographics, new technologies, and the move from an industrial to an information society, teacher educators need not only to prepare teachers for new ways of teaching, but also must adopt and model best practices for these new teaching methods. This study examines how several key strategies from Flipped Classroom theory can be adapted to an instructional methods course. Findings show that with careful curriculum design, both content and methods learning objectives can be taught and mastered with Flipped Classroom methods.
\end{abstract}

Keywords: Technology-Enabled Learning; Flipped Classroom; Teacher Education

\section{INTRODUCTION}

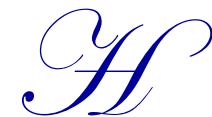

igher education and teacher education in particular are entering a time of transformation. With major forces like shifting demographics, new technologies, and the move from an industrial to an information society, teacher educators need not only to prepare teachers for new ways of teaching, but also must adopt and model best practices for these new ideas. Levine (2000) described nine inevitable changes that must take place in higher education to meet the needs of the information society. These nine changes are:

- Three basic types of colleges and universities are emerging. They are "brick universities," or traditional residential institutions; "click universities," or new, usually commercial virtual universities and "brick and click" universities, a combination of the first two.

- Higher education is becoming more individualized; students, not institutions, will set the educational agenda.

- $\quad$ The focus of higher education is shifting from teaching to learning.

- The traditional functions of higher education could become unbundled.

- $\quad$ Faculty members will become increasingly independent of colleges and universities.

- $\quad$ Degrees will wither in importance.

- $\quad$ Every person will have an educational passport.

- $\quad$ Dollars will follow the students more than the educators.

This study examines the second and third changes proposed by Levine (2000). With these changes in mind, the instructor flipped the classroom and moved much of the content online using open source technologies. This allowed more time to respond to student needs and utilize higher-level thinking skills (Anderson \& Krathwohl, 2000) in class meetings.

Must educators "give up what they have valued in the past in order to move forward?" Changing times mean that teacher educators need to examine teaching from new perspectives and make pedagogical choices based on preservice teachers' needs and those needs of the profession. Is there a place in the future of higher education for both valued traditional methods as well as new virtual technologies? 


\section{THE FLIPPED CLASSROOM}

The flipped classroom can take many forms. However, the core idea in all flipped classroom models is the use of teacher-created videos and interactive lessons so that instruction that used to occur in class is now accessed at home, in advance of class. Common elements of the flipped classroom model are: Provide an opportunity for students to gain first exposure prior to class, provide an incentive for students to prepare for class, provide a way to assess student understanding, provide in-class activities that focus on higher-level thinking skills (Brame, 2000; Bergmann \& Sams, 2012). With the inclusion of these elements "class becomes the place to work through problems, advance concepts, and engage in collaborative learning" (Tucker, 2012, p. 82). Effective flipped classroom teachers agree that it is not the instructional videos and other media that students view on their own that make this model so successful, but how the information from the media is integrated into face-to-face learning in the classroom (Bergmann \& Sams, 2012).

\section{Theoretical Framework}

What makes the Flipped Classroom successful in meeting higher-level cognitive learning objectives? The Flipped Classroom model utilizes two of the three key findings from Bransford, Brown, Cocking's (2000) How People Learn. Bransford and colleagues asserted that in order to develop competence in an area of inquiry, students must have the factual knowledge, understand these facts and concepts within the conceptual framework, and organize knowledge in ways to facilitate retrieval and application. In the flipped classroom model, students are required to use their new factual knowledge in class where they have access to immediate feedback from peers as well as the instructor. Immediate feedback is invaluable in correcting misconceptions and providing scaffolding for students to think about their developing understandings of the concept. The second key finding from Bransford et al. (2000) in effective flipped classroom models is a "metacognitive" approach to instruction where students define learning goals and monitor their own progress in meeting these goals. The idea of "thinking about their learning" is developed when students engage in higher-level thinking activities accompanied by meaningful peer/instructor interactions.

\section{History}

Like many pedagogical methods considered new and innovative by some, in reality the flipped classroom has been used in classrooms for over half a century; it is only the terminology that is new. During the open admissions and student power movements of the late 1960s and early 1970s, teachers developed collaborative learning and process-oriented pedagogies that integrated writing into the classroom in student-centered, peer group contexts. At this time, the method was considered "preparatory" work for class. In 2007, as slide share and podcast technologies emerged, several secondary teachers began posting class lectures for absent students to watch or listen before returning to class (Tenneson \& McGlasson, 2006). Students loved this option and began utilizing the slides for tutorials and remediation needs. This model was called "reverse instruction" and "inverted teaching" (Sparks, 2011). Further into the $21^{\text {st }}$ century, in 2011 , Net generation and iGeneration learners naturally gravitated toward this student-centered learning model. Teachers began to see the benefits in utilizing this model not only for absent students but for regular classroom lessons. Bergmann and Sams (2012) were pioneers in the field of using screencasting in education. These secondary teachers developed the methodologies educators know today as "Flipped Classroom" (Bergman, 2011). Today, in 2014, the "flipped classroom" model is used in a variety of classrooms in K-12 education and beyond. Educators post their media online for others to see and use. The prevalence of online videos has increased the use of "flipped classroom" models exponentially.

\section{Advantages of the Flipped Classroom}

In the years since the development of flipped classroom pedagogies, numerous researchers have examined the benefits and drawbacks to using this model. Overall, research findings demonstrate that effective implementation of the flipped classroom model will yield the following benefits: (a) providing one-on-one time with teachers, (b) students learning at own pace, (c) leveling the playing field, (d) addressing absenteeism,(e) providing an excellent diagnostic tool, and (f) students teaching students (Anger \& Roulet, 2012). 
As American demographics continue to show, the student population is increasingly diverse. Teachers need a way to free up time to meet and scaffold learning for individual students. Flipped classroom pedagogies allow more one-on-one time between teacher and student. Students are also able to "have it their way" with the ability to rewind, rewatch challenging concepts or skip over those concepts already mastered.

Flipped classroom methods also level the playing field for students whose parents may not be able to help them at home. With the "teaching" online, all students are equitably supported at home as long as they have the hardware, software, and Internet access needed.

Finally, with the help of certain computer software, teachers can quickly identify when students have mastered and not mastered the content. This allows teachers to implement flexible and purposeful grouping (Tomlinson, 2004) through which students can peer tutor classmates as needed, or move on to apply the content in a deeper way if it is clear that the content has been mastered

\section{Disadvantages of the Flipped Classroom}

Not everyone is a proponent of the flipped classroom model. Research thus far shows several key drawbacks to implementing the flipped classroom model (Block, 2010; Tucker, 2012; Tunks, 2012 ). The disadvantages of the flipped classroom can be consolidated into two areas: (a) increasing the digital divide, and (b) teacher overload. Both rural and urban schools have noted that access to Internet and digital devices is not a given in their student populations (Block, 2010). This can increase the digital divide already separating the "haves" from the "have nots." Also, the increased workload for teachers that now includes creating and monitoring online media, managing multiple students working on multiple assignments within multiple standards, motivating students to do their online assignments, and balancing state-mandated standardized testing goals within a "flipped classroom" model can overwhelm classroom teachers already struggling to balance all of their responsibilities (Block, 2010).

The following study will examine the advantages and address some successful tips for avoiding the disadvantages of flipping the college classroom.

\section{BACKGROUND FOR THE STUDY}

\section{School/Course Context}

This study was conducted in a small public university in North Carolina. Teacher education is the predominant major at this university. The instruction and management course that provides the content for this study is a required course and is placed within the context of four other upper-level methods courses (reading, math, social studies, and science). Students in this block of courses also participate in a 286 -hour field placement in a local elementary school.

\section{The Students}

Class size at this university is usually capped at 20 and this class had 19 students enrolled for the fall 2013 semester. Students were "traditional" in age (i.e., between 19 and 23) and were all female, White, and monolinguistic. All students were graduating seniors ready to student teach in the spring. The students all had access to computers/tablets/smart phones as well as the Internet. Of the 19 students, 3 utilized the Internet and computers at the university, while 16 had their own devices and Internet access off campus.

\section{The Instructor}

The instructor for this course is a veteran teacher with 12 years teaching experience at the elementary school level and 7 years teaching university-level students. She is a tenured professor who has taught this course consistently for 7 years. The instructor also teachers two other courses: (a) Integrating Technology nto the Elementary Classroom and (b) Teaching and Learning in the Digital Age. The instructor specializes in curriculum design with technology integration. 


\section{METHODOLOGY}

During the fall semester of 2013, students in an elementary education methods course focusing on classroom management and instruction were participants in this study. Before the semester began, the instructor revisioned the course pedagogy to represent the flipped classroom model. Much of the content instruction was transformed to digital formats (Voicethreads, slide shares, internet workshops, webquests, and online modules). Class meeting times were restructured from two 1.25-hour blocks per week to one 2.5-hour block once per week and focused on higher-level thinking skills such as applying, analyzing, and creating. Students were purposely grouped each week and worked collaboratively at three half-hour stations. The role of the instructor shifted each week depending on the learning objectives, but can be classified within the facilitator/guide model. Sometimes the professor would stay at one station and guide students through the learning goals there and other times the instructor would "float" from group to group, assessing student understanding and scaffolding student learning.

Each student participated in at least 8 of 10 class meetings and completed a midterm survey as well as an end-of-term evaluation. The instructor throughout the semester noted emails and spontaneous discussions about the class pedagogy as a form of informal feedback and data triangulation.

The researcher analyzed the data using a typological analysis system (Hatch, 2002). The same analysis procedures and sequence were used for analyzing all data from this study. The following steps were used in the data analysis:

1. Analysis of initial data sets (informal observations and discussions) and generated a list of potential analysis categories.

2. Informal data was then sorted into relevant categories.

3. Analysis of data across students looking for patterns, similarities, and differences by category.

4. Analysis of the midterm assessment data and the end-of-term evaluation data. A summary of overall themes and categories was written for each data set.

5. Themes and categories from the informal data sets were then compared with the summaries from the formal data sets and analyzed for congruency across categories.

\section{FINDINGS}

\section{Course Design}

Pedagogy in the flipped classroom model shifted from traditional teacher centered lessons about what and how one was to teach students to how students will learn the content and methods in this course. This was a fundamental shift and took some real thought and research on the part of the instructor. There are numerous pedagogical strategies that facilitate active learning in online environments (Tunks, 2012). Some effective pedagogies include technologies like Padlet, Voicethread, Bubbl.us, and Bitstrips where students utilize higher level thinking skills to apply and synthesize course content in a visual product. Even more student-centered and active online learning is now available in simulations and games. By maintaining systems of achievement, rewarding detail-oriented tasks and providing highly evolved character development systems, the gamification of any content "increases visibility and an awareness of the intricate. These flexible, digital systems promote the crafting and curating of incredibly complex processes, awarding reflection, analysis, metacognition, and social -- yet selfdirected -- revision of thinking and behavior" (Heick, 2011). With carefully selected online pedagogies, students were challenged, engaged, and informed.

The design of the online materials was also critical in the success of the "flipped" model. In a traditional delivery system instructors have the luxury of elaborating and explaining any curriculum ambiguities. Students can ask questions and get "just in time" teaching in each class meeting. In the online environment, students will feel isolated and frustrated with any ambiguities and can "turn off" if questions go unanswered for too long. Online tasks need to provide the same quality curriculum as their traditional counterparts but must utilize different methods, strategies, and materials to do so. 
In this project, there were several critical design strategies used that greatly enhanced student satisfaction in online tasks. First, students reported that they greatly appreciated a streamlined and easily navigated course website. I did this by using an LMS to create books with course assignments listed within the chapters. This was a great strategy and eliminated the "scroll of death." Also, students reported great satisfaction with the orientation book and video that helped them to better understand how to print chapters, find readings, and post assignments.

The literature about effective online instruction explains that predictability is best when creating the curriculum (Quality Matters, 2014). Students really liked the routine of when things are due and how/where to submit them. Course evaluations reported that students found the predictability of course assignments to be one of the biggest strengths in the course design. With their busy lives, they appreciated being able to plan their online time in advance.

Finally, students appreciated clear expectations for and descriptions of all assignments. I also provided some student examples of the assignments. Students really appreciated this and provided one more modality to visually explain the assignment. I also utilized screencasts for certain course content. Students reported that they really liked these because the screencasts showed them exactly what the directions described and how to access course materials or use new technologies.

I even used screencasts for "just in time" teaching. If I received several emails asking the same question about an assignment or technology, I just created and posted a screencast showing students what was meant by the directions. Students who were really struggling to understand a process, information, or assignment, reported the significant support these "just in time" screencasts provided. They learned the material and were prepared to utilize that content in class. The ability to meet the needs of individual learners through various strategies and technologies increases both student satisfaction and student achievement.

\section{Proactive Planning}

The documented negatives of a flipped classroom model were acknowledged and several strategies were used to neutralize the stressors of this design. One of the biggest benefits that negated the very real issue of access and knowledge was that all of the participants were full time students enrolled at the university and as such, had consistent access to Internet and devices. Students reported using the university computer labs on a regular basis because they did not own a mobile device or computer or it was unreliable. This consideration is vital in providing an equal opportunity for all students to achieve in the course. As noted by Block (2010), the Digital Divide is growing wider as technology advancement progresses. Successful online instruction must consider the topic of access.

Another very real deterrent to instructors utilizing the flipped model is teacher overload. Teachers today are stretched to the limit with teaching responsibilities and obligations. Beginning the flipped model can seem overwhelming. One successful strategy used in this study was to begin curriculum planning far in advance and identify and learn several technologies to put content online for students. I enrolled in a MOOC about the Flipped Classroom Model and utilized several of their design elements in my own course. Just like in traditional delivery systems, instructors need to seek out and borrow those ideas that work best. There is no need to reconstruct the wheel when someone else has already done the work. Also, lean into the Flipped Classroom Model. Do not try to move everything online the first time. Choose one or two learning goals to "flip" and add new content online as one feels more comfortable. Interestingly, students reported that they enjoyed the various types of learning modalities in the course. The online modules were scattered throughout the semester and students reported a "just right" amount of time online and face-to- face.

\section{Blended Pedagogy}

The flipped classroom model is very flexible and can be differentiated to meet the varied needs of both students and instructor. Successfully flipped classrooms integrate a variety of pedagogies both new and old. Many of those "best practices" from research verified sources can and should be used in the flipped classroom to promote higher level thinking skills, collaboration, and communication skills. While newer pedagogies incorporating media 
and technology can and should be used to provide initial exposure to content and free up more class time to analyze, apply, and evaluate that content. One lesson learned from this project was that any content put online for initial exposure needs to be clear and explicit. Students reported some confusion initially as they were asked to explore, reflect, and view various course resources. Since the content was new to the students, they needed more guidance to focus their attention and to prepare for the next session's face-to-face activities. This practice was a very delicate balance between constructivist methods and more teacher directed learning. I found that in the beginning, students were unfamiliar with the methods so they needed more structure but as students gained more experience with the Flipped Model, they began to take more responsibility for their learning and feel more confident in talking risks.

\section{CONCLUSIONS AND IMPLICATIONS FOR TEACHER EDUCATION}

This study demonstrates that effective teachers do not have to give up tried and true pedagogies in order to embrace new digital methods. Student-centered and learning outcome curriculum design are part of an effective "flipped" classroom. In fact, by purposely moving some instruction online, more time was dedicated to discussion, analysis, and authentic application of course learning objectives. These are the higher level thinking skills instructors often feel get pushed aside because of time constraints. The flipped model also allowed the instructor to facilitate student learning more effectively since students came to class with questions from the online assignment and the instructor could monitor online work, collaboration, and discussions to better plan face-to-face lessons. These experiences demonstrated a focus on student-centered learning where course instruction follows student need (Levine, 2000).

The challenges of using a Flipped Classroom Model are real but not insurmountable. Proactive strategies like course design and professional development were key in preventing teacher burnout. The Flipped Classroom is a new strategy to many and as such, will take some time and effort to learn, practice, and perfect. This effort needs to be recognized by administration and workload, pay scales, and professional development must be adjusted to support instructors in Flipped Classroom delivery models.

The world is rapidly changing and higher education must change to meet the new needs of learners, society, and employers. One way to keep the best of the old and new in higher education is with the Flipped Classroom Model where tried and true traditional pedagogies as well as new and emerging pedagogies exist side by side in course curricula. This new model of teaching and learning meets the needs of increasingly diverse student populations who expect customization and flexibility in their educational choices.

\section{AUTHOR INFORMATION}

Diane Marks is an Associate Professor in the Elementary Education Program in the Department of Curriculum \& Instruction at Appalachian State University. She teaches methods courses and technology/media courses to undergraduate students and graduate students. As well as 12 years as an elementary school teacher, Dr. Marks holds a Ph.D. in Curriculum and Instruction/Teacher Education from the University of Florida. She has published and presented at the international and national levels and her articles have appeared in National Teacher Education Journal, Journal of Technology Integration in the Classroom, AACE Journal, and North Carolina Middle School Association Journal.

\section{REFERENCES}

Anderson, L., \& Krathwohl, D. (Eds.) (2001). A taxonomy for learning, teaching, and assessing: A revision of Bloom's Taxonomy of Educational Objectives. New York, NY: Longman

Anger, B., \& Roulet, T. (2012). What is the flipped classroom model and why is it amazing? Forbes Business. Retrieved from http://www.forbes.com

Bergmann, J. (2011). The flipped classroom blog. Retrieved from http://blendedclassroom.blogspot.com/2011/05/history-of-flipped-class.html

Bergmann, J., \& Sams, A. (2012). Flip your classroom: Reach every student in every class every day. Washington, DC: International Society for Technology in Education. 
Block, J. (2010). Distance education and the digital divide: An academic perspective. Online Journal of Distance Learning Administration, 13(1). Retrieved from http://www.westga.edu/ distance/ojdla/spring131/block131.html

Bowen, J. A. (2012). Teaching naked: How moving technology out of your college classroom will improve student learning. Hoboken, NJ: Wiley.

Brame, C. (2013). Flipping the classroom. Nashville, TN: Vanderbilt University, Center for Teaching. Retrieved 2015 from http://cft.vanderbilt.edu/guides-sub-pages/flipping-the-classroom/

Bransford, J. D., Brown, A. L., \& Cocking, R. R. (2000). How people learn: Brain, mind, experience, and school. Washington, DC: National Academy Press.

Hatch, J. A. (2002). Doing qualitative research in educational settings. Albany, NY: SUNY Press.

Heik, T. (2011, December 15). The gamification of education: What school can learn from video games. Retrieved from http://www.edutopia.org/blog/gamification-education-terrell-heick

Levine, A. E. (2000, October 29). The future of colleges: 9 inevitable changes. The Chronicle of Higher Education, pp. 14-19. Retrieved from http://www.utb.edu/president/21CUC/Documents/Download/Article-TheFuture-of-Colleges-2012.pdf

Quality Matters (2014). The Quality Matters higher education rubric (5 ${ }^{\text {th }}$ ed.). Retrieved from https://www.qualitymatters.org/rubric

Sparks, S. D. (2011, September 28). Lectures are homework in schools following Khan Academy lead. Education Week. Retrieved from http://www.edweek.org/ew/articles/2011/09/28/05khan_ep.h31.html

Tenneson, M., \& McGlasson, B. (2006, April). The classroom flip. Presentation at Fontbonne University, Missouri Teaching and Learning Mentor Program. Retrieved from www.fontbonne.edu/upload/TheClassroomFlip.ppt

Tomlinson, T. A. (2004). How to differentiate instruction in mixed-ability classrooms (2nd ed.). Alexandria, VA: Association for Supervision \& Curriculum Development (ASCD).

Tucker, B. (2012). The flipped classroom. Education Next, 12(1), 82-83. Retrieved from http://educationnext.org/the-flipped-classroom/

Tunks, K. W. (2012). An introduction and guide to enhancing online instruction with Web 2.0 tools. Journal of Educators Online, 9(2), 1-16. 


\section{NOTES}

